\title{
Article
}

\section{Sex counts: An examination of sexual service advertisements in a UK online directory}

Kingston, Sarah and Smith, Nicola

Available at https://clok.uclan.ac.uk/31302/

Kingston, Sarah orcid iconORCID: 0000-0002-9226-1915 and Smith, Nicola (2020) Sex counts: An examination of sexual service advertisements in a UK online directory. The British Journal Of Sociology, 71 (2). pp. 328-348. ISSN 0007-1315

It is advisable to refer to the publisher's version if you intend to cite from the work. http://dx.doi.org/10.1111/1468-4446.12727

For more information about UCLan's research in this area go to http://www.uclan.ac.uk/researchgroups/ and search for <name of research Group>.

For information about Research generally at UCLan please go to http://www.uclan.ac.uk/research/

All outputs in CLoK are protected by Intellectual Property Rights law, including Copyright law. Copyright, IPR and Moral Rights for the works on this site are retained by the individual authors and/or other copyright owners. Terms and conditions for use of this material are defined in the policies page.

\section{CLoK}

Central Lancashire online Knowledge www.clok.uclan.ac.uk

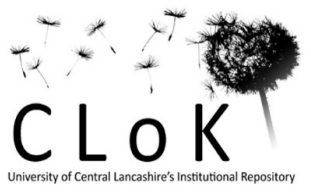




\title{
Sex Counts: An Examination of Sexual Service Advertisements in
}

\section{a UK Online Directory}

\begin{abstract}
Internationally, sex work research, public opinion, policy, laws, and practice are predicated on the assumption that commercial sex is a priori sold by women and bought by men. Although there is an extant literature on male sex work, scarce attention has been devoted to lesbian, bisexual, trans, or queer/questioning (LGBTQ) sex working as well as women who pay for sex. This is as much an empirical absence as it is a theoretical one, for the ideological claim that women comprise the 'vast majority' of sex workers is rarely, if ever, exposed to empirical scrutiny. Focusing on the UK, we address this major gap in evidence in order to investigate whether women comprise the 'vast majority' of sex workers. We do so by presenting large-scale data gained from the quantitative analysis of 25,511 registered member-profiles of an online escort directory. Our findings demonstrate that women are not alone in selling sexual services: while two-thirds of advertisements self-identify as 'Female', one in four are listed as 'Male'. In addition, less than half list their sexual orientation as 'Straight'; and nearly two-thirds advertised to female clients. Our study thus challenges prevailing heteronormative assumptions about commercial sex, which erase LGBTQ sex workers and other non-normative identities and practices, and which we argue have important political, practical and theoretical consequences.
\end{abstract}

Key Words: online sex work research, prostitution policy, violence against women 


\section{Introduction}

A rich body of literature has highlighted how commercial sex is experienced, constructed, practised and embodied in a multiplicity of different ways (see for instance Agustin, 2007; Cabezas, 2009; Kotiswaran, 2011). However, in some respects this enormously valuable body of scholarship continues to reproduce dichotomous understandings that sex is sold by women and bought by men. Whilst research has shown that lesbian, gay, bisexual, transgender and queer/questioning (LGBTQ) identities and practices exist, as well as straight, cisgender (cis) ${ }^{1}$ women who buy sex, the presumption that women compose the 'vast majority’ of sex workers (Zatz 1997: 279; Harris, Nilan \& Kirby 2011: 387; Hilman 2012: 39; Geist 2016: 2) continues to influence political, practical and theoretical debates surrounding sex work. And yet, this claim is made in the absence of a comparative quantitative study that investigates whether commercial sex can indeed be assumed to be 'overwhelmingly heteronormative' (Carline 2011: 320) in this way. This unevidenced belief, we suggest, reinforces problematic assumptions that sex workers exist as an identifiable class of persons to be 'known,' regulated and disciplined (Foucault, 1978), and leads to policy approaches, practical interventions and theoretical debates that are narrow in focus.

This highlights the need not only for theoretical critiques of the heteronormative assumptions that structure debates about commercial sex, but also for research into the empirical claims that inform such assumptions. If it cannot simply be assumed that there is a 'type' of person who sex works, then this suggests that essentialist framings of commercial sex are in turn problematic. In this article, we offer empirical discussion in order to destabilise the truth claims that underpin the dominant discourses surrounding commercial sex discussed above. Our empirical analysis is thus used purposefully to speak to broader conceptual and political debates surrounding the essential 'reality' of 
commercial sex. More specifically, we are interested in the question of whether commercial sex is characterised not by homogeneity but by diversity, including along axes of gender identity and sexual orientation. We should be clear from the outset that, in asking this question, we do not mean to suggest that there is one all-defining answer that can be provided in a single study. Instead, we are interested in troubling the empirical assumption that sex workers are always-already embodied in particular ways, e.g. that the 'vast majority' are women. The discussion that follows is therefore not intended to capture or describe the totality of the contemporary sex industry. Instead, we want to 'interrupt' (Weber 2017) dominant framings through empirical discussion in order to highlight the potential variety of experiences in online commercial sexual encounters. In so doing, we hope to open up new space for the political critique of dominant preconceptions of commercial sex in the UK and elsewhere.

Our overarching aim in this article is to use empirical evidence to contest ideologically-driven beliefs, and we do so by undertaking quantitative research. Focusing on the UK, we present original findings gained from a quantitative analysis of 25,511 registered member-profiles of an online escort directory. This is, to our knowledge, the largest-scale quantitative comparative analysis of sex worker online profiles to-date. Online advertisement sites represent meaningful sites for critical analysis as the Internet has rapidly become established as one of the central terrains of sex worker advertisement and promotion internationally (Sanders et al. 2017). In reporting findings from a very large and gender-inclusive dataset, our research offers an original contribution to knowledge by interrogating whether some of the underlying assumptions of the sex industry are in fact tenuous and distorted.

Our study does not support claims that the 'vast majority' of sex workers are straight, cis women advertising to straight, cis men. Instead, our evidence-base points to 
heterogeneity in the UK's online sexual services industry along a number of axes including gender identity and sexual orientation. Whilst the majority of sex workers advertisements in our study were listed as 'Female', and thus provides an evidence base that was previously lacking, this majority was far from 'vast'. While this might seem a rather pedantic point, we highlight how 'vast majority' claims close off critical space to recognise and respond to LGBTQ sex workers politically, practically and theoretically.

Such empirical findings are interesting in their own right but also have wider significance in challenging the heteronormative stereotypes that underpin contemporary debates in scholarly work, public opinion and policy practice. These heteronormative assumptions proscribe that women are passive vessels for men's sexual pleasure. Thus, our empirical data alerts us of the need to resist rather than to reinforce essentialist readings of commercial sex as automatically attached to women's bodies, and which equate heterosexuality with sexuality itself. Given that such assumptions play out in academic debates and policy practice not only in the UK but also internationally, our findings have international import by highlighting the importance of exposing and contesting the essentialist logics that continue to frame such debates. Our study therefore not only presents insights into the configuration of the UK online sexual services advertising industry, but also aims to open up new space to think differently about the theory and practice of commercial sex. In theorizing sex work in terms of diversity rather than dualisms, we can begin to resist the simplistic stereotypes that justify the denial of LGBTQ sex workers' rights and which naturalize heterosexual desire in the process.

\section{Debates about commercial sex}

There is now a vast and diverse body of scholarship on the global sex industry, and this has charted the multifarious ways in which commercial sex is experienced, practised and 
constructed in different political, economic and cultural spaces (see for instance Bernstein 2008; Cabezas 2009; Kotiswaran 2011; Delacoste 2018). For example, cis male sex working has been examined both qualitatively and quantitatively in America (Logan, 2010) Australia (Minichello et al, 2002; Scott et al, 2005) Costa Rica (Shifter \& Aggleton, 1999), Dominican Republic (Padilla, Castellanos, Guilamo-Ramos, Reyes, Sánchez, \& Soriano, 2009), India (Shinde, Setis, Row-Kavi, Anand, \& Jerajani, 2009), the United Kingdom (Whowell, 2010) and Vietnam (Clatts Giang, Goldsamt, \& Yi, 2007). Likewise, research on trans sex working has been explored in Argentina (dos Ramos Farías, Garcia, Reynaga, Romero, Vaulet, Fermepín, Toscano, Rey, Marone, Squiquera, González, Basiletti, Picconi, Pando, \& Ávila, 2011), and Mexico (Infante, Sosa-Rubi, \& Cuadra, 2009).

Yet, despite showing that LGBTQ sex workers exist in the UK and elsewhere, this body of scholarships fails to compare different gender identities and sexual orientations quantitatively. A national quantitative comparison such as this has important political, practical and theoretical consequences, because it is commonly assumed that commercial sex is underpinned by an oppositional gender binary, without providing an evidence base for these claims. Thus, policy approaches, interventions by practitioners and theoretical claims made about the nature of sex work are forged upon ideological heteronormative assumptions about sex - that men are sexual subjects (and thus clients), and women are sexual objects (and thus sex workers) - rather than an empirical evidence base.

These assumptions can be seen most obviously in scholarly discourses surrounding male demand, which appeal explicitly to the notion that commercial sex not only causes violence against women under certain conditions, but that it constitutes violence against women in and of itself. As Melissa Farley (2003: xvi-xvii) argues, prostitution is the 'bedrock of male domination of women', and Janice Raymond (2013: 71) defines prostitution as 
'violence against women, a human rights violation, and a crime.' These conceptual claims are, in turn, explicitly justified on the empirical basis that the 'vast majority' of sex workers are women. Darren Geist (2016: 2), for instance, contends that it is 'men - the consumers and organisers of sex' who benefit most from the sex industry, for the 'vast majority of "sex workers" are women,' without citing empirical evidence to support such claims. Indeed, even those who seek to challenge gender-based assumptions about sex work reproduce such framings despite the absence of an evidence base. For example, Noah Zatz (1997: 279, 306) argues that commercial sex 'is a site of powerful sexual pluralism, capable of contesting hegemonic constructions of sexuality,' but suggests that 'it is nonetheless true that the vast majority of prostitutes are women with male clients.' Likewise, Anna Carline critiques the politics of abolitionism in the UK but argues that, while there is a 'sizeable sex market for gay men', the sex industry is organised around 'the satisfaction of male heterosexual desire' (Carline 2011: 320). Thus, although there is a substantial body of literature on sex work, a great deal of it remains predicated on the ideal-type of the female sex worker and male client rather than exposing this to critical scrutiny.

Importantly, the female sex worker/male client heteronormative binary also structures prostitution policy debates in the UK and elsewhere. The assumption that the 'vast majority' of sex workers are women can be observed internationally. For example, the Government of Canada's (2014: 1) Protection of Communities and Exploited Persons Act S.C. 2014, c. 25, which created an offence that prohibits purchasing sexual services, identifies that prostitution 'has a disproportionate impact on women and children'. Similarly, in England and Wales, prostitution policy claims to be gender neutral and yet national and local prostitution policing strategies have focused primarily on on-street sex workers who are women (Whowell, 2010). Furthermore, the House of Commons Home Affairs Committee (2017: 4) called for research to understand the nature and prevalence 
of prostitution in England and Wales before further law reform would be considered, because the committee recognized gaps in existing knowledge, but did so on the explicit premise that the 'majority' of sex workers are women. In the UK, these political views have become incorporated into the Crown Prosecution Service's (2019:1) legal guidance on the prosecution of sexual offences, whereby it explicitly identifies 'those that incite and control prostitution - the majority of whom are men' and 'the sellers of sex - the majority of whom are women'. Thus, prostitution is understood as 'sexual exploitation' that, 'due to its gendered nature', should be approached using the CPS's 'Violence against Women and Girls ... legal guidance' (ibid:1). Indeed, according to the Home Office (2004:17), a 'prostitute user ... is a man' and those who sell sex are 'women'. Again, the claim that sex workers are de facto women and their clients men is asserted but not backed up by substantive empirical evidence.

At the local level, too, such stereotypes prevail and influence local attitudes, practices, and service provision for sex workers. For example, Kingston (2013) finds that residents, business employees, police officers and local councilors invariably identify sex workers as women and clients as men, predominantly focusing intervention on street sex workers. Opinion polls designed to gauge public attitudes towards sex work have themselves fed into the assumption that only men pay for sex from women. The UK IPSOS Mori (2008a; 2008b) survey on prostitution in 2008, for instance, asked if 'In your opinion, is it acceptable or unacceptable for a man to purchase sex with a woman?' without asking the same question with gender roles reversed.

The repetitive articulation of such narratives - so dominant, and so widespread has closed off vital space to ask whether we 'know' that sex workers are a priori straight, cis women selling sex to straight, cis men? This question is significant because it frames 
scholarly, media and political debates, and yet the answer to it is already treated as a given. As Smith argues,

[T]he focus on women and girls tends to be justified (if it is justified at all) on the grounds that the 'vast majority' of sex workers are female; indeed, a huge amount of theoretical weight rests upon the shoulders of this empirical assertion and yet it is never really interrogated empirically. (Rather, the words 'vast majority' are uttered and, like a rabbit in a hat, all of the male and transgender sex workers magically disappear) (Smith, 2012:590).

Thus, whilst research has documented the diverse identities and experiences of sex workers, as shown above, a quantitative study to investigate whether the 'vast majority' are women has been lacking. Is the sex industry characterised not by homogeneity but by heterogeneity, including in terms of gender identity and sexual orientation? Our empirical research seeks to address this fundamental question about sex work in order to challenge the politics of essentialism that structure contemporary debates about commercial sex.

\section{Methodology}

Our methodology was informed by a post-positivist epistemology, that is by the desire to politically contest (rather than to scientifically test) truth claims surrounding the 'types' of identities and practices involved in the sex industry. ${ }^{2}$ Although quantitative methods are seldom used in post-positivist research (Barkin \& Sjoberg 2015), they can fruitfully be used to challenge essentialist logics through the charting of difference (Lawson 1995). If understood as a set of tools rather than as a set of principles, quantitative methods can be harnessed to 'explore a wide variety of constitutive, performative and relational questions' (ibid: 854). However, as Lawson contends, it is important for post-positivists to approach 
quantitative research carefully, in particular to avoid reproducing assumptions surrounding 'an atomistic, closed system world view of individuals statically classified and assumably replaceable' (Lawson 1995: 454). For this reason, we did not make use of inferential statistics but instead engaged in the simple exercise of counting. As Lawson rightly notes, counting can be used productively to challenge assumptions about the sameness of human experience through the charting of difference - a central aim of the research. ${ }^{3}$ We therefore employed counting in order to assess the quantitative claim that the 'vast majority' of sex workers are straight, cis women, as well as other assertions as to the homogeneity of the industry.

Moreover, our study focused on an Internet site rather than, for instance, on-street sex work on the grounds that any understanding of sex work empirically requires consideration of how the sex industry is disparate, fluid and evolving. Although much focus historically has centred on street sex work and its associated nuisances, the industry is increasingly moving and expanding online, and research on sex work must not overlook these developments (Bernstein 2007). Recent years have witnessed the rise of social networking sites and the increasing use of sites such as Twitter since its introduction in 2006. Internationally, the internet has emerged as a medium through which sex workers are able to communicate, network, advertise and sell services (Sanders 2013). While the use of the internet for the purposes of sex working is not particularly new, in recent years the Internet has emerged as the major site of the contemporary sex industry due to a confluence of broad-scale cultural and technological shifts, including the sexualisation of mainstream culture (Bernstein 2007). The Internet is not only a 'virtual' space in which particular sexual services are being produced and consumed online (e.g. webcamming) but it also shapes the processes and practices through which physical interactions are being instigated and negotiated (Cunningham and Kendall 2011; Rocha et al 2010; Sharpe and Earle 2003). 
Online sites that advertise commercial sexual services thus constitute important but often ignored sites of critical inquiry (Pruitt 2005). These online spaces offer a unique opportunity to look beyond physical sex work spaces and locations such as brothels, streets, flats or parlours, as many sex workers work independently. For example, researchers have used online spaces in order to analyse and investigate the activities and dialogue between escorts and sex buyers (Langanke and Ross 2009; Rocha et al 2010; Sharpe and Earle 2002); to communicate with potential participants and advertise research (Hammond 2010; Koken et al. 2004; Sanders 2008); to interview and survey sex workers nationally and internationally (Jenkins 2010; Milrod and Monto 2012); and to access websites, forums and blog pages to gain the contact details of sex workers for interviews or survey (Parsons et al 2004). Most studies have been qualitative rather than quantitative in nature, such as Hammond's $(2010 ; 2018)$ interviews with UK-based clients of commercial sex via Punternet; or Pitcher's interviews with sex workers in the UK, who were accessed through her online networks and escort websites (see also inter alia McLean; Redman 2016). ${ }^{4}$ Those quantitative studies that do exist have tended to restrict their focus to particular 'types' of sex work or sex workers, such as women-only websites or male-to-male escorting. For example, research by Castle and Lee (2008) provided a content analysis of female escort websites, whereas Logan's $(2010 ; 2017)$ study of advertisements placed on the largest online male sex work site in the United States (US) focused specifically on male sex workers (see also Kumar et al, 2017; Lee-Gonyea et al. 2009; Minichiello \& Scott 2017). As enormously valuable as all of these studies are, research into online advertising sites has tended to focus on particular modes of selfidentification and embodiment.

In order to address this major gap in pre-existing research, we compiled data from a prominent online directory of people who advertise commercial sexual services. The site was 
chosen because it is one of the largest directories internationally, and we focused specifically on the UK because the site itself is predominantly UK-based. The sample comprised 25,511 registered members of the site who advertised as escorts in the UK and who had logged in within two months. The data was obtained by counting member profiles using the site's internal search engine, which was used to view aggregate figures, and we calculated percentages based upon these numbers (accessed on 15-16 June 2017).

Of member profiles, we limited our sample to those listed specifically as escort profiles on the grounds that levels of overall site membership have altered significantly over time, that not all members advertise sexual services, and not all members are active on the site. (For example, at the time of our search, only $71 \%$ of total members had logged in within two months). ${ }^{5}$ We did not, however, restrict our sample to fully verified members. This is because, in order to become a fully verified member, it is necessary to provide proof of identity such as a scan of a passport or driving license. Due to the highly stigmatised and often criminalised nature of the industry, many sex workers are understandably not prepared to provide such documentation to websites. To include only fully verified members in our sample would, therefore, provide a highly misleading picture, as all this would reveal is how many members were willing to provide proof of identity to the site administrators.

Several ethical issues should be highlighted before proceeding. First, research into online communities can risk violating the privacy of members, not least by leading to their identification, and this is particularly an issue when websites are openly accessible to the general public (as is the case with the site in question). Although these risks are much lower for aggregate quantitative data analysis than for other types of research (British Psychological Society 2013), this must weighed against the fact that sex workers are a highly stigmatized population who lack full legal and social protection. Furthermore, research has demonstrated that sex workers may face physical and emotional violence from family members and friends 
if their sex working becomes known (Kinnell 2008). We therefore do not include the name or address of the website here because this 'may compromise the anonymity of individuals or have a negative effect on an online community' (British Psychological Society 2013:18).

Second, in order to protect the privacy of members, some sexual services and escort websites clearly specify that no information may be downloaded or shared without permission from the site. We therefore sought, and were granted, written permission from the administrators to undertake the research on the understanding that the site would not be named, and they also provided us with additional data.

Third, some escorts explicitly state that the information contained on their individual profiles must not be used for research purposes. We therefore did not view any individual profiles for the research but instead accessed the search engine results only. It would have been ideal to secure consent for each individual member to access the aggregate data but, given the very large number of profiles advertised on the site, this was simply not possible hence why we secured permission directly from the site administrators to ensure that our research did not breach the site's terms and conditions. Ours is not the first time that research on the sex industry has been conducted in this way (Kumar et al 2017; Minichiello \& Scott 2017), but we recognize that the ethics of data scraping are debated (Markham and Buchanan 2012). Yet so too are all other modes of research employed to study the sex industry. For example, quantitative 'tick box' surveys, whilst highly valuable, often involve self-selecting participants and so can privilege those with the time/access to participate; qualitative interviews can involve considerable power imbalances between interviewers and interviewees; etc. (see for instance Karnieli-Miller et al 2008; Richards \& Schwartz 2002; Daigle 2015). ${ }^{6}$ The research has received institutional ethical approval from the University of Birmingham. 
Having outlined both why and how our study was conducted, we now outline our key findings before turning to a discussion of their significance to the scholarly literature and policy practice.

\section{Findings}

\section{Gender identity}

The most dominant stereotype of commercial sexual exchange is the figure of the sex worker is always already female. Our findings, however, challenge this stereotype. Just over twothirds $(67 \%)$ were listed as 'Female' (presumably ${ }^{7}$ cisgender female), and more than one in four (28\%) of the escort profiles were listed as 'Male' (presumably cisgender male). In addition, $4 \%$ of the profiles were listed as 'TV/TS ${ }^{8}$ Male,' and $1 \%$ were listed as 'TV/TS Female'. We could locate no option for non-binary profiles.

Although it is often assumed that cis male and trans escorts are but a tiny minority, this was not reflected in the escort profiles in our sample. Admittedly, street sex working and indoor establishments are reported in the academic and policy literature to be more commonly occupied by cis female sex workers (Weitzer, 2005), but this may be more of a question of representational visibility than empirical presence. What we can see through examining online advertisements on this site is that cis male and trans escort profiles are being advertised online in large numbers when compared to female escorts.

\section{Sexual orientation}


Debates about commercial sex are also framed by heteronormative assumptions that both clients and sex workers identify as heterosexual. Yet we found that fewer than half (42\%) of escort profiles listed a sexual orientation of 'Straight.' Over half (57\%) of the escort profiles in our sample were listed as 'Bi-Curious' or 'Bi-Sexual' (24\% and 33\% respectively), although just $0.7 \%$ were listed as 'Gay.' As Figure 1 reveals, cis male profiles were much more likely to identify as straight than cis female, trans female, and trans male profiles. Apart from cis men, most profiles identified as bi-sexual or bi-curious. It is important to note that people's virtual profiles do not necessarily map on to the sexual and/or gender identities that they embrace or perform in their daily lives. Yet it is interesting that - in an industry that is seen as 'overwhelmingly heteronormative' - the majority of escort profiles are not in fact listed as 'Straight'.

[Insert Figure 1 here]

\section{Clients}

As previously noted, public, political, and academic debates have invariably assumed that clients are heterosexual men. Although it is impossible to determine the extent to which men buy sex, because of the illicit and often illegal nature of the sex industry, our findings show that nearly two-thirds of the sample (63\%) advertised to women as well as to couples (69\%), compared to four-fifths (79\%) advertising to men. (Unfortunately, we could not locate an option to search for non-binary clients, but this certainly does not mean that they are not an empirical presence).

[Insert Figure 2 here]

If we focus on the gender of clients as specified in the advertisements, we found that, although nearly all (99\%) of cis female profiles advertised to men, nearly half (49\%) also did 
so to women and nearly two-thirds $(62 \%)$ to couples. Cis male member profiles, in contrast, mainly advertised to women and couples, with $29 \%$ advertising to men. Most trans male and trans female profiles advertised to men, but also to women and couples. Although advertisements to clients clearly cannot be assumed to translate into client numbers, it is nevertheless performatively significant that cis female, trans, gay, bi and couple clients are being positioned as potential consumers in this way. It also supports previous research that has noted that women and couples buy sex (Lee-Gonyea et al, 2009), as well as studies on male-to-male escorting (see for instance Morrison and Whitehead, 2007; Walby, 2012; Collins, 2012; Minichiello and Scott, 2014).

\section{Ethnicity}

Stereotypes about the ethnicity of those involved in the sex industry have been documented in previous research. A study by Kingston (2013), for example, found that the general public characterized clients as being from a different ethnic group to themselves in an attempt to create distance between themselves and purchasers of sex. In addition, sex trafficked victims and pimps were assumed to be non-British, and this was related to migration patterns and movements within the European Union. The findings of the 'Big Brothel' survey by The Poppy Project, which reported for instance that 7 workers were 'White', 146 were 'Oriental' and 103 were 'Asian' (Bindel and Atkins, 2008) supports these assumptions.

[Insert Figure 3 here]

Yet our findings were that the overwhelming majority of escort profiles to specify 'Ethnicity' $(n=13,933)^{9}$ were listed as 'White' $(80 \%)$ in contrast to 6\% 'Black,' 6\% 'Mixed,' 4\% 'Asian,' 2\% 'Latin,' $0.6 \%$ 'Indian,' $0.2 \%$ 'Chinese,' 0.1\% 'Arabic,' and 1\% 'Other.' ${ }^{10}$ As for 
gender identity and sexual orientation, such figures cannot be assumed to map neatly on to particular bodies, but they nevertheless highlight the need to challenge racialised stereotypes of sex workers as exotic 'Others' (Penttinen 2008).

Age

Previous research has estimated the 'average' age of sex workers to be from 27 years (Pruitt, 2005) or 28 years (Cunningham and Kendall 2011), with the mean age as 29 for women and 24 for men (Weinberg, Shaver \& Williams 1999), but this obscures the wide range of ages advertised. The stated ages of escorts on the site ranged from 18 years (the minimum age at which sexual services can be advertised under UK law) to 91 years. While nearly half (47\%) of profiles listed ages that were in the twenties, a sizeable minority advertise ages in the thirties $(28 \%)$ and forties $(16 \%) .{ }^{11}$ Indeed, cultural pressures to appear 'youthful' mean that sex workers may significantly understate their ages on their profiles. Data provided by the site administrators revealed that, of fully verified escorts $(n=10,556),{ }^{12}$ women understated their age by an average of two years whereas men did so by an average of one year.

[Insert Figure 4 here]

\section{Calling}

Interestingly, despite common assumptions that there are defined spaces where sex work takes place (such as in flats, brothels on in red-light districts), we found that escort profiles were more likely to advertise out-calls $(74 \%)$ in which they would travel to the location of the client. That said, a majority (68\%) advertised in-calls in which they would see clients in their own location, and $48 \%$ offered both out-calls and in-calls. ${ }^{13}$ Cis male profiles were the most likely to advertise out-calls, and trans female profiles were the most likely to offer in-calls. 
These findings challenge common assumptions held by the general public that there are designated spaces where sex is bought and sold (Cooper, 2014; Kingston, 2013). For example, out-calling can offer opportunities for sex workers to separate 'home' from 'work' as part of broader strategies to manage the distinction between personal lives and sex working (Sanders, 2005). Out-calling to hotels can also increase the safety of sex workers, for instance by enabling them to work together whilst minimizing the risk of criminal prosecution of brothel-keeping charges under existing UK law (The Sexual Offences Act 1956).

[Insert Figure 5 here]

Although many escorts and sex workers prefer to work independently, the law encourages lone working as they seek to avoid criminal prosecution for brothel keeping charges. Yet it is well documented that this law increases the likelihood that they will experience violence as workers operating alone (Kinnell, 2008). In the UK, the criminalisation of clients also increases the risks to both workers and clients because they are more likely to meet in remote locations in order to avoid the police (Sanders \& Campbell, 2007). This risk to sex workers has been duly recognised by both the French and Luxembourg governments when they rejected plans to make it an offence to purchase sex on the grounds that it would increase the dangers for sex workers, as they would be more likely to work alone if the law was introduced (Senat France, 2014; Senat, Luxembourg, 2014).${ }^{9}$ In addition, the general public have been shown to recognise the risks to sex workers and clients that criminalisation can bring, and as a result have expressed their support for licensing and regulation (Kingston, 2013). 


\section{Locality}

The locations where people advertised were dispersed across the UK, but key regions included London (23\%), the South East (14\%), the North West (10\%), and East of England (10\%). Within the key regions there was a fairly limited degree of geographical concentration within major cities: for example, $34 \%$ in Wales listed Cardiff; $40 \%$ in the West Midlands listed Birmingham; and 30\% in the North East listed Newcastle.

[Insert Figure 6 here]

Of profiles to specify travel preferences $(n=11,121)$, just $13 \%$ indicated that they would not travel at all. In contrast, $26 \%$ would travel for an hour, and $23 \%$ would travel for two hours or more.

These findings are significant for the study of geographies of commercial sex, for it is often assumed that sex work is primarily concentrated in big cities, and that it is confined to particular spaces (such as brothels; red-light districts) (Cooper 2014). Our study suggests that the online sex industry may be rather more dispersed across the UK than is commonly thought. It is also interesting that the majority of profiles advertised out-calls, for this suggests that sex workers are willing to work 'on the move' rather than being tied to specific locations (e.g., dedicated premises). This may be an effect of the Internet making it easier for sex workers to advertise more broadly and remotely. The context of criminalization is also important here, for it increases the likelihood of displacement, relocation and independent working as sex workers and their clients seek to evade the police (Sanders 2004). 


\section{Services advertised}

Our data points to considerable diversity in the types of services offered and rates advertised. Over one hundred different types of activity were listed on the site, the most popular of which were striptease (93\%), oral sex (80\%), and massage (80\%). In addition, profiles could identify which services were not on offer: for instance, $82 \%$ specified that they would not receive bondage, domination, sadism and masochism (BDSM), and 65\% stated that they would not give BDSM. This undermines popular assumptions that sex workers sell their 'bodies' for clients to 'use' at will (see, for instance, Pateman 1999). Instead, there is considerable specificity and diversification in terms of the type of services that individual escorts do and do not offer.

It is often assumed that - because sex workers have multiple partners - they are 'automatically a health risk', even though there is compelling evidence that sex workers can and do act as health educators (Sanders, 2006: 2435). In fact, $90 \%$ of the profiles explicitly stated that unprotected penetrative sex was not on offer, although the figure was lower $(56 \%)$ for profiles that did not offer oral sex without protection. In contrast, a study of the young people aged 15-25 finds that more than half (75.9 per cent) of those who were sexually active have had unprotected sex with casual partners (de Visser et al, 2014: 542), and another involving 16-25 year olds finds that one-third have had unprotected sex with multiple or casual partners (Lim et al. 2009: 483).

\section{Rates}

It has previously been argued that sex work is a profession in which women can earn considerably more than men (MacKinnon, 1987). Although this is supported by our study, we 
also found that people advertising as trans escorts were the most likely to list very high rates, with $17 \%$ of trans male profiles and $24 \%$ trans female profiles advertising hourly rates of $£ 200$ or more. This compared to $3 \%$, compared with $14 \%$ for cis female profiles. We found that $65 \%$ of cis male profiles advertised rates of less than $£ 100$ compared to $9 \%$ of cis female profiles, $29 \%$ of trans male profiles, and $12 \%$ of trans female profiles. Whether these fees vary and are later negotiated is unclear, although previous research has demonstrated that fee negotiations do sometimes take place (Gertler, Shah \& Bertozzi, 2005).

[Insert Figure 7 here]

It has been suggested that women have chosen this occupation because of the financial benefits that this type of work has over others forms of work: higher pay, flexible working arrangements, greater control and management (Bernstein, 1999). Yet, it is interesting that in a society that is characterized by a deep and persistent gender pay gap (Tharenou, 2013), women are often earning more than men for sex work. This cannot simply be accounted for by market size, for it is trans escorts - who represent the smallest market who are often charging the highest rates. Instead, given the diversity in rates (i.e. for cis female, cis male and trans escorts alike), and also given the huge variety in services advertised, the figures could be read as evidence of diversification and market specialization rather than as denoting a simple dichotomy between 'high paid women' and 'low paid men.'

\section{Discussion}

Our research points to a diversity of identities and practices in the contemporary sex industry. These empirical findings are new, surprising and perhaps even counter-intuitive 
in the context of widely-held assumptions about the 'types' of identities and practices involved in commercial sex. For instance, the End Demand (2016: 2) campaign group has called for the UK Parliament to criminalize the purchase of sexual services, asserting that 'the majority of people exploited through prostitution are women and girls and the majority of those who pay for sex are men. ${ }^{, 14}$ In contrast to this stereotype of the female worker and male client, our data shows that a sizeable minority of escort profiles are listed as 'Male,' that many do not self-identify as 'Straight,' and that the majority explicitly advertise to women and couples. To be clear, our findings do not show that the sex industry is not a gendered industry, for it is indeed the case that the majority of escort profiles were listed as 'Female,' just as the majority also advertised to men. What they do suggest, though, is that the sex industry may be gendered in rather more complex ways than is conventionally assumed, for sexual desire does not only exist in its heterosexual articulations. To focus only, or even primarily, on the female worker/male client binary is to overlook the potential for divergent identities, activities, and expressions in the contemporary sex industry - and this binary is in turn underpinned by 'vast majority' claims. Clearly, it is impossible to do justice to the rich complexity of performances, experiences and embodiments involved in the online sex industry in a single quantitative study. Our figures therefore cannot be assumed to reflect the transparent 'reality' of online sex work. Nevertheless, our research challenges prevailing stereotypes of the sex industry as a monolithic bloc of uniform advertised or offered practices. Our data is instead suggestive of the high levels of diversification, specification and specialization that have come to represent the hallmarks of contemporary capitalism (Phipps 2015).

These original findings are significant in highlighting the need to rethink dominant stereotypes and popular prejudices about sex workers and their clients. As we have discussed, it is precisely the potential for complexity that scholarly and political debates 
about commercial sex often obscure. Most notably, they continue to reproduce age-old sexist stereotypes that women are sexual objects and men are sexual subjects. As noted earlier, anti-trafficking agendas are organised around the notion that trafficked 'victims' of prostitution are women. This can be seen in both academic debates and in the activities of NGOs and campaign groups, such as the Coalition Against the Trafficking of Women. In the UK, as well as internationally, calls to follow a 'Swedish' or 'Nordic' model of criminalization appeal directly to constructions of sex workers as victimized women and their clients as predatory men. The Swedish Institute, in full support of the ban on purchasing sexual services, has argued that 'it is shameful and unacceptable that, in a gender equal society, men obtain casual sexual relations with women in return for payment' (Swedish Institute 2010: 4). Likewise, across European political forums MEPs can be seen to perpetuate these gendered assertions in the context of debates on the trafficking for sexual exploitation. For instance, Mary Honeyball MEP and Vice Chair for the European Parliament's Committee on Women's Rights and Gender Equality has claimed that 'the most effective way of combating the trafficking of women and underage females for sexual exploitation and improving gender equality is the model implemented in Sweden, Iceland and Norway (the so-called Nordic model)' (Honeyball 2014:1).

Notably, it is not only national policy but also local-level practice that can be shaped by problematic stereotypes of sex workers. In the UK, the systematic erasure of LGBTQ sex workers in political discourse means that there are few projects commissioned to provide support services to them (Bryce et al. 2015). There is therefore 'an urgent need for policy revisions to ensure that future provision is inclusive, relevant to the needs of all sex workers and recognizes the rights to public protection for all' (ibid: 252). Given that many on- and off-street physical spaces are frequently dominated by cis 
female sex workers, other sex workers may feel excluded from these spaces and the projects that provide support services there, hence why they may advertise online in large numbers. It is often these visible parts of the industry that are assumed to reflect the industry as a whole (Scoular 2015), and these assumptions not only obscure the complexity of the industry but also materialize in the support services commissioned to provide outreach for sex workers. This highlights the need for political debates and policy practice to recognize and respond to the diversity and complexity in the industry that our study has identified.

The heteronormative imaginaries of sex work, which are propped up by empirical claims, thus play out as material realities that not only shape public policy and practice but also the everyday lives of sex workers and their clients. Importantly, they work to increase the visibility of some - often the most vulnerable, such as street workers - while creating invisibilities for others. For example, research by Kingston et al (forthcoming) shows that women clients feel they are ignored by policy makers because of their assumed non-existence, in turn meaning that they can more easily evade police detection and prosecution in countries that have created a criminal offence of paying for sex. To be able to 'go under the radar' is particularly important in contexts such as the UK, where legislation has made it a criminal offence to purchase sexual services from a forced or coerced person. That women in the sex industry are being rendered visible only in certain types of ways - as street workers, as victims of sex trafficking, but never as clients - not only reflects gendered, racialized, and classed hierarchies but also serves to produce them. It is poor and migrant women, after all, that dominant discourses focus on - and it is poor and migrant women who are in turn being targeted by the police, as the English Collective of Prostitutes (2016) repeatedly report. This further underscores the need for political 
debates and policy practice to challenge heteronormative logics and, in so doing, to resist the denigration and criminalisation of sex workers that such logics help to produce.

\section{Limitations}

Although our original findings are important in challenging the dominant stereotypes that continue to frame scholarly and political debates, there are several limitations with our research. First, our findings relate only to a specific period of time. We attempted to account for inactive profiles, but it is likely that our two-month window of escort activity did not capture sporadic users: those who 'dip in' and 'dip out' of sex working. Commercial sex has been described as 'the ultimate precarious labor' (Sanders \& Hardy 2013: 16) due to its high levels of part-time, casualized, temporary and contingent work, and it is not uncommon for some sex workers to leave the industry and then return months or years later due to a change in their financial, occupational or personal circumstances.

Second, the findings from this study are taken from just one online directory. There are many other advertising sites and agencies that cater for this wide-ranging market, and many sex workers do not advertise online. The 'digital divide' is well documented, as those who may be economically disadvantaged or computer illiterate may be unable to engage online (Bolger et al. 2003). Street sex workers can be difficult to locate online because they often do not have access to the internet or mobile enabled devices. Likewise, sex workers are not necessarily limited to one sex scene, with some street sex workers working on the street and also from their own homes. Thus, our findings cannot be extrapolated to make concrete assertions about the rest of the UK sex industry. Nor does the data provided give an indication of the aggregate volume of sale and purchase of sexual services across the UK - although it should be noted that because of the hidden and secretive nature of the sex industry globally, is it not possible to provide 
such data. As outlined earlier, our aim was not to produce 'representative' findings as this would rest upon problematic assumptions about the sameness and replicability of human experience.

Third, just as our sample did not include all sex workers in the UK, so too it cannot be assumed that all profiles in our sample were from bona fide sex workers. Previous research has ascertained that people often engage in 'identity performance' and 'impression management' whilst engaging online (Boyd \& Jeffrey 2006). For some, creating a fantasy online personality can produce feelings of liberation from the constraints of physical form, or a mode of 'empowering exhibitionism' (De Laat 2008: 68). Agents and managers may also post profiles of particular escorts but then inform clients that this escort is not available but that another is; we call these impersonated sex workers. Others may advertise sexual services online, but this does not 'convert' into clients or service types. Thus, some advertisements may only reflect someone's ambition to sex work rather than its actual practice; we call these prospective sex workers. Furthermore, sex workers who advertise online often have multiple profiles to feed into niche markets (for example, by advertising as a dominatrix who performs sadomasochism and bondage on one profile, whilst advertising more mainstream services on another) (Pruitt \& Krug 2010). The use of multiple profiles can therefore itself operate as an effective advertising tool, as it enables escorts to access a wide range of clients.

Fourth, we do not claim to have captured the 'reality' of sex working online. Clearly, escorts' advertisements cannot be assumed to be 'real' (since advertising is not the same as selling), but this does not mean that they can simply be dismissed as 'fake' either. Indeed, as post-positivist researchers, we reject outright any notion that there is some kind of neat division between 'authentic' and 'fabricated' identities, which overlooks the performative character of all identities (Butler 1990). Nor do we regard 
sexuality as a 'thing' that lies beneath or beyond social existence and which either hides or declares its 'reality' (Foucault 1978). For example, if someone sets up an escort profile in order to articulate their fantasies surrounding sex work (but they never actually engage in sex work), is this not in itself a meaningful performance? Is fantasy not in itself 'real' in some senses? If we accept that sexual subjectivities are performed in virtual spaces as well as physical ones, and if we also accept that the boundaries of what does and does not constitute 'sex work' are always blurred (Cabezas 2009), then online advertisements are clearly worthy of attention in their own right.

Fifth, the study was very much bounded by the search engine tools available to us. Given that profiles were organized according to pre-set categories, these may not have reflected the self-identities of those advertising. For example, the gender options available were 'Male,' 'Female,' 'Couple MF,' 'Couple MM,' 'Couple FF,' 'TV/TS Male,' 'TV/TS Female,' 'TV/TS Couple MF,' 'TV/TS Couple MM,' and 'TV/TS Couple FF,' with no reference to alternate identities such as non-binary, genderqueer, intergender or agender. As noted, people often engage in identity performance through sex work, and so the gender and/or sexual identities that people perform when escorting cannot be assumed to match up neatly with the sexual and/or gender identities they perform in other contexts of their lives. The data thus inevitably obscure a far more complex and fluid picture than can be captured through search engine results.

Our study thus highlights the need for future research to further deepen and expand the analysis offered here. Given that our research was limited to one online UK based directory at a particular moment in time, future studies could examine a larger number of international sites (see, for instance, Minichiello \& Scott 2017) to interrogate whether the patterns we identify here play out in other national or local contexts. However, researchers must recognize that sex workers migrate extensively for sex work 
(Agustin 2006; Blerk 2008), and thus may advertise on multiple sites. Similarly, longitudinal research could explore how the configuration of the online sex industry shifts over time, for example in terms of the geographical distribution of escort profiles.

The research also points to other areas of enquiry that were beyond the scope of our study but that nevertheless warrant further analysis. Given that we found many couples advertising online, further studies on couples are needed. Although research has identified the experience of sex workers who provide services to couples and couples who have purchased sex, this has been somewhat limited (Kingston et al, forthcoming). In addition, the data on the geographical distribution of sex work online points to the need for more research on rural parts of the UK and elsewhere. It is hardly surprising that research has focused on major cities given the visibility of the industry, access to organizations that support sex workers and a high density of workers in city centers. Although online research such as ours may capture some of the experiences of sex workers who provide services in more rural areas, future studies could interrogate sex working in rural communities. In addition to further quantitative analyses, qualitative and/or mixed methods research could be undertaken to explore these complexities and nuances in more depth. Further quantitative analysis of advertisement sites would also be useful, for example to explore the relationships between particular variables (such as those between age, sexuality and rates of pay; whether people charge more per hour in the south than in the north of the country; and whether those who advertise as men, women or trans are more likely to offer specific services).

Finally, qualitative research could investigate whether advertisements translate into bookings, although this would need to consider the diversity of sex worker practices and experiences. For example, building up a client base takes time and whilst a person might not be providing sexual services at the time of the research, this does not mean that 
they will not provide sexual services at some point. Kingston et al's (forthcoming) research on women who pay for sexual services alone and as part of a couple, has shown that many men sex workers work part time and inconsistently, and thus may be misinterpreted as a 'bogus' sex worker when their inconsistent work patterns are not taken into account. We define a bogus sex worker as someone who does not intend to, has sold sexual services, nor works in the industry as an agent or manager, but creates a bogus profile for personal gratification or in order to victimize or exploit sex workers. Like any other area of research, it is possible that some of our sample were bogus or impersonated sex workers, and others were career sex workers (who work full time as a sex worker), part-time sex workers (who have another part-time or full-time job), yoyo sex workers (who dip in and out of sex work) and prospective sex workers (who show ambition to sex work, but their adverts do not translate into bookings). Qualitative research could also interrogate whether a person engages in career sex work or other modes of sex work (as listed above); profile log-ins over a one-to-five year period could be tracked to determine user activity. In addition, the question of whether user activity is reflective of a pattern of sex working or something else (e.g., they work indoors or on the street when they are inactive online, or they were unwell for a long period or were incarcerated) could be explored in interviews; as could further research into how, why and by whom these adverts are constructed.

\section{Conclusion}

As we have explored in this article, the quantitative claims that underpin debates about sex work are no abstract theoretical matter, for they also play out very directly in appeals to empirical 'facts.' Such claims conjure up images of a (most often) unspecified number 
that is rarely, if ever, tested empirically. This matters because, as Shirin Rai (2017) notes, numbers not only have descriptive value in capturing our everyday lives but also have substantive and symbolic value, not least in informing public policies. Numbers hold particular power when they are assumed to be beyond contestation, for they can be deployed as depoliticising tactics that close off space to contest the very issues that most deserve critical scrutiny. Such is the case with commercial sex.

As our analysis of an online sexual services directory illuminates, the advertised or offered identities and practices involved in commercial sex are multifarious, not monolithic. For example, our findings show a sizeable minority of adverts are listed as cis male or trans and, whilst the majority of profiles advertise to men, similar percentages advertise to women and couples. The female sex worker/male client binary is thus troubled by our data. Whilst previous research has identified the diverse forms of sex work practiced and experienced (see for example, Campbell et al. 2018; Sanders et al. 2017), a large-scale comparative analysis that either supports or rebuts claims about the heterogeneous nature of the sex industry has been lacking. Our study seeks to address this gap by presenting data from, to our knowledge, the largest-scale comparative quantitative analysis of sex worker advertisements to date. This study has captured the intersectional experiences of online commercial sex workers in the UK.

In so doing, our study raises important questions about current policy and laws that have been justified on the grounds that prostitution is a form of violence against women, as well as current practices that provide support services primarily to streetbased, cis female sex workers. We have sought to politicize such claims not by rejecting numbers per se, but rather by deploying numbers as counter-narratives to dominant depictions of sex workers. Such depictions are politically questionable not only because they do violence to the richness and variety of human experience but also because they 
help to justify the stigmatization and criminalization of sex workers. We therefore hope that our research will help to carve out greater conceptual and political space to recognize that, if gender, sexuality, embodiment and desire take many forms, then the sex industry is surely no exception to this.

\section{Acknowledgements}

We would like to thank Dave Campbell, Emma Foster, Chris Grover, Vivien Lowndes, Suzanne Ost, and Terry Thomas for reading and commenting on earlier drafts of this article. We would also like to thank Sylvia Walby, Alisdair Gillespie, and the editors of British Journal of Sociology for their support and belief in this article. Finally, many thanks to the reviewers for their insightful feedback.

\section{Notes}

\footnotetext{
${ }^{1}$ We use 'cisgender' (and the abbreviation 'cis') to refer to a 'positive identification of a non-trans identity' (Aultman 2014: 61).

${ }^{2}$ Positivism and post-positivism are best understood as 'ideal types rather than bounded categories' (Barkin \& Sjoberg 2017: 14). We employ them heuristically to distinguish between those modes of research which assume that 'reality is objective, that objective research is possible, meaning is fixed, and power [in knowledgeproduction] is not a variable that needs to be taken into account' (positivism), and those in which 'reality is socially constructed, knowledge is monist, meaning is not fixed, and meaning-making practices are powerinfused' (post-positivism) (Sjoberg 2015:1009). For in-depth discussions of positivism and post-positivism, see Smith (1996) and Jackson (2011).

${ }^{3}$ For an analysis of the gendered politics of counting and not-counting, see Davies \& True (2017). We use counting in the spirit of other quantitative studies such as those into poverty and income inequality that report
} 
gender, ethnicity, age, etc. as a political rather than scientific endeavour (see for instance Bennett \& Daly, 2014).

${ }^{4}$ Although see for instance Logan (2010), McCarthy et al (2014), Sanders et al. (2016), Sagar et al. 2015).

${ }^{5}$ In contrast, $96 \%$ of escort profiles had logged in within two months, and $72 \%$ within one week. Levels of membership for escort profiles have remained fairly constant: for example, on 29 Febuary 2012 there were 27,369 escort profiles, of whom $95 \%$ had logged in within two months and $69 \%$ within one week. Similarly, on 5 August 2015, there were 27,408 escort profiles, of whom $95 \%$ of people advertising as escorts had logged in within two months and $69 \%$ within one week.

${ }^{6}$ For an in-depth discussion of the ethics of big data, see Herschel \& Miori (2017).

${ }^{7}$ We use the term 'presumably' since they included no 'TV/TS' profiles.

${ }^{8}$ The site uses the acronym 'TV/TS' but, as 'TV' derives from a term that is often considered derogatory (GLAAD, 2017), we use the adjective 'trans' as it is widely accepted by the trans community. We use the term 'cis' to denote non-trans members, although it does not appear on the site itself, in turn reflecting the naturalisation of cisnormativity. We refer to trans male and trans female profiles rather than to trans men or trans women since a profile may be listed as 'TV/TS male' by a trans woman rather than a trans man due to the risk of transphobic violence (for a discussion of which, see Stryker 2006).

${ }^{9}$ We recognise that ethnicity is not interchangeable with race but use the term 'ethnicity' as this is the term used by the site itself. Not all members specify ethnicity, and so the sample size differs from that of the overall sample, hence why we report number $(n=)$ here.

${ }^{10}$ It is also worth noting that, of the profiles in our sample which specified their first and second language $(\mathrm{n}=13,790)$, English was more than four times more likely to be listed as a first language $(80 \%)$ than a second language $(20 \%)$.

${ }^{11}$ These findings also support those obtained by Sanders, Connelly \& King (2016) in their survey of 240 registered members of National Ugly Mugs (NUM).

${ }^{12}$ We did not restrict our overall sample to fully verified members for the reasons outlined earlier. However, we are grateful to the site administrators for providing us with this data on the minority of members who were prepared to verify their membership, as it allowed for comparison between the stated ages and verified ages of these particular members. As the sample size is different from our overall sample, we report the number $(n=)$ of that sample here. 
${ }^{13}$ Lee-Gonyea, Castle \& Gonyea's examination of 83 international websites found that only $1.2 \%$ offered in calls, $19.3 \%$ offered out-calls, with the largest percentage (47\%) offering both in-calls and out-calls and $32.5 \%$ providing no information (2009:338).

${ }^{14}$ Similarly, an open letter to Amnesty International, which opposed decriminalisation and which was signed by over 600 people including prominent celebrities, explicitly referred to sex workers as 'human beings bought and sold in the sex trade, who are mostly women' (Abdel-Hamid et al, 2015).

\section{References}

Abdel-Ahmid, M. 2015 Letter to Salil Shetty, Steven W. Hawkins and the Amnesty International Board of Directors, July 17, 2015. Retrieved from http:// catwinternational.org/Content/Images/Article/621/attachment.pdf

Agustín, L. M. 2007 Sex at the margins: migration, labour markets and the rescue industry. London: Zed Books.

Agustín, L. 2006 The Disappearing of a Migration Category: Migrants Who Sell Sex. Journal of Ethnic and Migration Studies, 32(1), 29-47.

Balfour, R \& Allen, J. 2014 A Review of the Literature on Sex Workers and Social Exclusion. Commissioned by the Department of Health. Retrieved from https://assets.publishing.service.gov.uk/government/uploads/system/uploads/attachment data/file/303927/A_Review_of_the_Literature_on_sex_workers_and_social_exclusion.pd $\underline{\mathrm{f}}$

Barkin, J. S., \& Laura, S. 2015 Calculating Critique: Thinking Outside the Methods Matching Game. Millennium: Journal of International Studies, 43(3), 852-871. doi:10.1177/0305829815576819

Bennett, F. \& Daly, M. 2014 Poverty through a gender lens: evidence and policy review on gender and poverty. Retrieved from 
https://www.spi.ox.ac.uk/sites/default/files/Gender_and_poverty_Bennett_and_Daly_fina

\section{1_12_5_14_28_5_14.pdf}

Bernstein, E. 2007 Temporarily yours: Intimacy, authenticity, and the commerce of sex. Chicago: University of Chicago Press.

Bindel, J. \& Atkins, H. 2008 Big brothel: A survey of the off-street sex industry in London. London: Eaves Housing for Women.

Bolger, N., Davis, A. \& Rafaeli, E. 2003 Diary methods: Capturing life as it is lived. Annual Review of Psychology, 54(1), 579-616.

Boyd, D., \& Jeffrey, H. 2006 Profiles as conversation: Networked identity performance on Friendster. Proceedings of the Hawai'i International Conference on System Sciences. Kauai, HI: IEEE Computer Society.

British Psychological Society 2013 Ethics guidelines for internet-mediated research INF206/1. Retrieved from http://www.bps.org.uk/system/files/Public \%20files/inf206guidelines-for-internet-mediated-research.pdf

Bryce, A., Campbell, R., Pitcher, J., Laing, M., Irving, A., Brandon, J., Swindells, K., \& Safrazyan, S. 2015 Male escorting, safety \& National Ugly Mugs: Queering policy \& practice on the reporting of crimes against sex workers. In Mary Laing, Katy Pilcher \& Nicola Smith (eds) Queer Sex Work (pp.245-254). London: Routledge.

Butler, J. 1990 Gender Trouble: Feminism and the Subversion of Identity. Psychology Press.

Cabezas, A. L. 2009 Economies of desire: Sex and tourism in Cuba and the Dominican Republic. Philadelphia: Temple University Press.

Carline, A. 2011 Criminal justice, extreme pornography and prostitution: Protecting women or promoting morality? Sexualities, 14(3), 312-333. 
Carline, A., \& Scoular, J. 2015 Saving Fallen Women Now? Critical Perspectives on Engagement and Support Orders and their Policy of Forced Welfarism. Social Policy and Society, 14(1), 103-112.

Castle, T., \& Lee, J. 2008 Ordering sex in cyberspace: a content analysis of escort websites. International Journal of Cultural Studies, 11(1), 107-121.

Clatts, M. C., Giang, L. M., Goldsamt, L. A., \& Yi, H. 2007 Male sex work and HIV risk among young heroin users in Hanoi, Vietnam. Sexual Health, 4(4), 261-267.

Cooper, E. 2014 'It's better than daytime television': Questioning the impacts of Blackpool's massage parlours on people and place. Doctoral Thesis: Lancaster University.

Cunningham, S., \& Kendall, T. D. 2011 Prostitution 2.0: The changing face of sex work. Journal of Urban Economics, 69(3), 273-287.

Davies, S, E., \& True, J 2017 The Politics of Counting and Reporting Conflict-Related Sexual and Gender-Based Violence: The Case of Myanmar. International Feminist Journal of Politics, 19, no. 1: 4-21.

De Laat, P. 2008 Online diaries: Reflections on trust, privacy, and exhibitionism. Ethics and Information Technology, 10(1), 57-69.

Delacoste, F. 2018 ed. Sex Work: Writings by Women in the Sex Industry. Cleis Press. dos Ramos Farías, M. S., Garcia, M. N., Reynaga, E., Romero, M., Vaulet, M. L. G., Fermepín, M. R., Toscano, M. F., Rey, J., Marone, R., Squiquera, L.,González, J. V., Basiletti, J.,Picconi, M A., Pando, M. A., \& Ávila, M. M. 2011 First report on sexually transmitted infections among trans (male to female transvestites, transsexuals, or transgender) and male sex workers in Argentina: high HIV, HPV, HBV, and syphilis prevalence. International Journal of Infectious Diseases, 15(9), 635-640.

English Collective of Prostitutes. 2016 Police raids, arrests and legal cases. Retrieved from http://prostitutescollective.net/legal-cases/. 
End Demand 2016 Written evidence submitted by End Demand. Retrieved from http://data.parliament.uk/writtenevidence/committeeevidence.svc/evidencedocument/hom e-affairs-committee/prostitution/written/29036.pdf

Enke, A. 2012 Transfeminist Perspectives in and beyond Transgender and Gender Studies. Philadelphia: Temple University Press.

de Visser, R, O., Badcock, P, B., Simpson, J, M., Grulich, A, E., Smith, A., Richters, J., \& Riseel, C. 2014 Attitudes toward sex and relationships: the Second Australian Study of Health and Relationships. Sexual Health, 11, 397-405.

Farley, M. 2003 Preface: Prostitution, trafficking and traumatic stress, in M. Farley (Ed.) Prostitution, trafficking and traumatic stress (pp. xi-xxii). The Haworth Maltreatment \& Trauma Press: Binghamton.

Foucault, M. 1978 The History of Sexuality, Vol. 1: An Introduction. New York: Vintage Books.

Gertler, P., Shah, M., \& Bertozzi, S. 2005 Risky business: The market for unprotected commercial sex. Journal of Political Economy, 113(3), 518-550.

Geist, D. 2016 Amnesty International's Empty Promises: Decriminalisation, Prostituted Women, and Sex Trafficking. Dignity: A Journal on Sexual Exploitation and Violence, $1(1), 1-26$.

Gould, A. 2001 The Criminalisation of Buying Sex: the Politics of Prostitution in Sweden. Journal of Social Policy, 30(3), 437-456.

Government of Canada 2014 Protection of Communities and Exploited Persons Act

S.C. 2014 , c. 25 , Retrieved from http://laws-

lois.justice.gc.ca/eng/AnnualStatutes/2014_25/page-1.html 
Hammond, N. 2010 Tackling taboos: Men who pay for sex and the emotional researcher. In K. Hardy, S. Kingston \& T. Sanders (Eds.), New sociologies of sex work (pp.59-74). Surrey: Ashgate.

Harris, M., Nilan, P., \& Kirby, E. n.d Risk and Risk Management for Australian Sex Workers. Qualitative Health Research 21, no. 3: 386-98.

Hilman, J. 2012 Sexuality and Aging: Clinical Perspectives. New York: Springer.

House of Commons Home Affairs Committee 2017 Prostitution: Third report of session 2016-17. Retrieved from https://publications.parliament.uk/pa/cm201617/cmselect/cmhaff/26/26.pdf

Honeyball, M. 2014 We must be ambitious when it comes to prostitution - Not accept it as a fact of life. Retrieved from http://www.huffingtonpost.co.uk/mary-honeyball/protitution$\underline{\text { sex-work-law_b_4649359.html }}$

Infante, C., Sosa-Rubi, S. G., \& Cuadra, S. M. 2009 Sex work in Mexico: vulnerability of male, travesti, transgender and transsexual sex workers. Culture, Health \& Sexuality, 11(2), 125-137.

IPSOS Mori. 2008a Public's views on prostitution. Retrieved from https://www.ipsosmori.com/researchpublications/researcharchive/2308/Publics-views-on-prostitution.aspx IPSOS Mori. 2008b GEO Survey: Prostitution 1 September 2008 Topline Results. Retrieved from https://www.ipsos-mori.com/Assets/Docs/Polls/poll-prostitution-topline- august.pdf

Jakobsson, N., \& Kotsadam, A. 2011 Gender equity and prostitution: An investigation of attitudes in Norway and Sweden. Feminist Economics, 17(1), 31-58.

Jenkins, S. 2010 New technologies, new territories: Using the Internet to connect with sex workers and sex industry organisers. In K. Hardy, S. Kingston \& T. Sanders (Eds.), New sociologies of sex work (pp.91-108). Cullumpton: Ashgate. 
Kingston, S. 2013 Prostitution in the Community: Attitudes, Action and Resistance. London: Routledge.

Kingston, S., Hammond, N., \& Redmand, S. forthcoming Women who buy sex: Converging Sexualities? London: Routledge.

Koken, J. A., Bimbi, D. S., Parsons, J. T., \& Halkitis, P. N. 2004 The Experience of stigma in the lives of male internet escorts. Journal of Psychology \& Human Sexuality, 16(1), 13-32.

Kotiswaran, P. 2011 Dangerous sex, invisible labor: Sex work and the law in India. New Jersey: Princeton University Press.

Kumar, N., Minichiello, V., Scott, J., \& Harrington, T. (2017). A Global Overview of Male Escort Websites. Journal of Homosexuality, 64(12), 1731-1744.

Langanke, H., \& Ross, M. W. 2009 Web-based forums for clients of female sex workers: development of a German internet approach to HIV/STD-related sexual safety. International Journal of STD \& AIDS, 20(1), 4-8.

Lawson, Victoria. 1995 The politics of difference: Examining the quantitative/qualitative dualism in post-structuralist feminist research. The Professional Geographer 47(4): 44957.

Lee-Gonyea, J. A., Castle, T., \& Gonyea, N. E. 2009 Laid to order: Male escorts advertising on the internet. Deviant Behavior, 30(4), 321-348.

Lim, M. S. C., Hellard, M. E., Aitken, C. K., \& Hocking, J. 2009 Surveillance of STI risk behaviour among young people attending a music festival in Australia, 2005-08. Australian and New Zealand Journal of Public Health, 33, 482-484.

Logan, T. D. 2010 Personal characteristics, sexual behaviors, and male sex work: A quantitative approach. American Sociological Review, 75(5), 679-704. 
Logan, T.D. 2017 Economics, Sexuality, and Male Sex Work, Cambridge: Cambridge University Press.

Mai, N. 2012 The Fractal Queerness of Non-Heteronormative Migrants Working in the UK Sex Industry. Sexualities 15, no. 5-6: 570-585.

Markham, A., \& Buchanen, E. 2012 Ethical Decision-Making and Internet Research: Recommendations from the AoIR Ethics Working Committee. Retrieved 2 November 2018 http://www.expertise121.com/curriculum/3.pdf

McCarthy, B., Benoit, C., \& Jansson, M. 2014 Sex Work: A Comparative Study. Archives of Sexual Behavior, 43(7), 1379-1390.

Milrod, C., \& Monto, M. A. 2012 The hobbyist and the girlfriend experience: Behaviors and preferences of male customers of internet sexual service providers. Deviant Behavior, 33(10), 792-810.

Minichiello, V., Marino, R., Browne, J., Jamieson, M., Peterson, K., Reuter, B., \& Robinson, K. 2002 Male Sex Workers in Three Australian Cities. Journal of Homosexuality, 42(1), 29-51.

Minichello, V., \& Scott, J. 2017 Research shows distribution of online male escorts, by nation. Retrieved December from https://research.qut.edu.au/aboutmaleescorting/2017/11/01/number-of-online-maleescorts-by-nation-2/

Padilla, M., Castellanos, D., Guilamo-Ramos, V., Reyes, A. M., Sánchez Marte, L. E., \& Soriano, M. A. 2008 Stigma, social inequality, and HIV risk disclosure among Dominican male sex workers. Social Science \& Medicine, 67(3), 380-388.

Parsons, J., T, Bimbi, D. S., \& Halkitis, P. N. 2001 Sexual compulsivity among gay/bisexual male escorts who advertise on the internet. Sexual Addiction \& Compulsivity, 8(2), 101-112. 
Pateman, C. 1999 What's wrong with prostitution? Women's Studies Quarterly, 27(1/2), 5364.

Penttinen, E. 2008 Globalization, prostitution and sex-trafficking: Corporeal politics. London: Routledge.

Phipps, A. 2014 The politics of the body: Gender in a neoliberal and neoconservative age. Cambridge: Polity Press.

Pitcher, J. 2015 Sex work and modes of self-employment in the informal economy: Diverse business practices and constraints to effective working. Social Policy and Society, 14(1), 113-123.

Pruitt, M. V. 2005 Online boys: Male-for-male internet escorts. Sociological Focus, 38(3), 189-203.

Pruitt, M. V., \& Krull, A. C. 2010 Escort advertisements and male patronage of prostitutes. Deviant Behavior, 32(1), 38-63.

Rai, S. 2015 Magic Numbers: Number Magic. A Critical Review of Their Value. University of Warwick.

Raymond, J, G. 200310 Reasons for Not Legalising Prostitution. Coalition Against Trafficking in Women International. Retrieved from http://prostitutionresearch.com/tenreasons.html.

Rocha, L. E. C., Liljeros, F., \& Holme, P. 2010 Information dynamics shape the sexual networks of Internet-mediated prostitution. Proceedings of the National Academy of Sciences, 107(13), 5706-5711.

Sagar, T., Jones, D., Symons, K., \& Bowring, J 2015 The Student Sex Work Project: Research Summary, Retrieved from http://www.thestudentsexworkproject.co.uk/wpcontent/uploads/2015/03/TSSWP-Research-Summary-English.pdf 
Sanders, T. 2004 A continuum of risk? The management of health, physical and emotional risks by female sex workers. Sociology of Health \& Illness, 26(5), 557-574.

Sanders, T. 2005 'It's just acting': Sex workers' strategies for capitalizing on sexuality. Gender, Work \& Organization, 12(4), 319-42.

Sanders, T., \& Hardy, K. 2013 Sex work: The ultimate precarious labour? Criminal Justice Matters 93(1), 16-17.

Sanders, T., Connelly, L., \& King, L. J. 2016 On Our Own Terms: The Working Conditions of Internet-Based Sex Workers in the UK. Sociological Research Online, 21(4), 1-14.

Sanders, T., Scoular, J., Campbell, R., Pitcher, J., \& Cunningham, J. 2017 Internet sex work: Beyond the gaze. Basingstoke: Palgrave.

Scott, J., Minichiello, V., Mariño, R., Harvey, G., P., Jamieson, M., \& Browne, J. 2005 Understanding the New Context of the Male Sex Work Industry. Journal of Interpersonal Violence, 20(3), 320-342.

Scoular, J. 2015 The Subject of prostitution: Sex work, law and social theory. London: Routledge.

Scoular, J., \& Carline, A. 2014 A critical account of a 'creeping neo-abolitionism': Regulating prostitution in England and Wales, Criminology and Criminal Justice, 14(5), 608-626.

Sharp, K., \& Earle, S. 2002 Cyberpunters and cyberwhores: Prostitution on the internet. In Y. Jenkins (Ed.), Dot. cons: Crime, deviance, and identity on the Internet (pp.36-52). Cullumpton: Willan Publishing.

Shepherd, L. J. 2008 Gender, Violence and Security: Discourse as Practice. Zed Books. 
Shepherd, L, J., \& Sjoberg, L. 2012 Trans- Bodies in/of War(s): Cisprivilege and Contemporary Security Strategy. Feminist Review 101, no. 1: 5-23. Retrieved from https://doi.org/10.1057/fr.2011.53.

Shinde S, Setia MS, Row-Kavi A, Anand V, Jerajani H. 2009 Male sex workers: Are we ignoring a risk group in Mumbai, India? Indian Journal of Dermatology, Venereology and Leprology, 75, 41-6. Retrieved from http://www.ijdvl.com/article.asp?issn=0378-

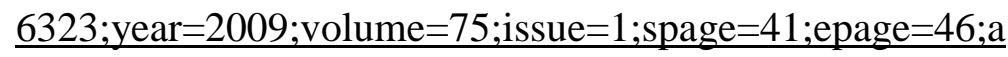

Sigurðardóttir, J. 2014 Gender equality did not fall into our laps without a struggle. Women in Parliaments: Global Forum. Retrieved from: http://www.wip-gf.net/news/johannasigurdardottir-gender-equality-did-not-fall-our-laps-without-struggle

Smith, N. 2012 Body Issues: The Political Economy of Male Sex Work. Sexualities 15, no. 5-6: 586-603.

Swedish Institute 2010 Prohibition of the purchase of sexual services. An evaluation 19992008. Retrieved from

http://www.government.se/content/1/c6/11/98/61/2ac7d62b.pdf

Uy, J. M., Parsons, J. T., Bimbi, D. S., Koken, J. A., \& Halkitis, P. N. 2004 Gay and bisexual male escorts who advertise on the internet: Understanding reasons for and effects of involvement in commercial sex. International Journal of Men's Health, 3(1), 11-26. Retrieved from http://www.mensstudies.info/OJS/index.php/IJMH/article/view/436 van Anders, S. M. 2015 Beyond Sexual Orientation: Integrating Gender/Sex and Diverse Sexualities via Sexual Configurations Theory. Archives of Sexual Behavior, 44(5), 11771213.

Van Blerk, L. 2008 Poverty, migration and sex work: youth transitions in Ethiopia. Area, 40, 245-253. 
Weber, C. 2017 "What Is Told Is Always in the Telling": Reflections on Faking It in 21st Century IR/Global Politics. Millennium 45, no. 1.

Weinberg, M. S., Shaver, F. M., \& Williams, C. J. 1999 Gendered sex work in the San Francisco tenderloin. Archives of Sexual Behavior, 28(6), 503-521.

Weitzer, R. 2005 New directions in research on prostitution. Crime, Law and Social Change, $43,211-235$.

Whowell, M. 2010 Male Sex Work: Exploring Regulation in England and Wales. Journal of Law and Society, 37(1), 125-144.

Zatz, N, D. 1997 Sex Work/Sex Act: Law, Labor, and Desire in Constructions of Prostitution. Signs, 277-308. 
SEX COUNTS 